\title{
The social and structural determinants of sexual and reproductive health and rights in migrants and refugees: a systematic review of reviews
}

*Dianne Egli-Gany, ${ }^{\text {*}}$ Wafa Aftab, ${ }^{2}$ Sarah Hawkes, ${ }^{3}$ Laith Abu-Raddad, ${ }^{4}$ Kent Buse, ${ }^{5}$ Fauziah Rabbani, ${ }^{2}$ Nicola Low ${ }^{1}$ and Kristine Onarheim ${ }^{3}$

Institute of Social and Preventive Medicine, University of Bern, Bern, Switzerland (Correspondence to: Dianne Egli-Gany: degli-gany@bluewin.ch). ${ }^{2}$ Department of Community Health Sciences, Aga Khan University, Karachi, Pakistan. ${ }^{3}$ Centre for Gender and Global Health, Institute for Global Health, University College London, London, United Kingdom. ${ }^{4}$ Kent Buse, Director, Healthier Societies Program, The George Institute for Global Health, Imperial College London, United Kingdom.

\begin{abstract}
Background: The sexual and reproductive health and rights (SRHR) of migrants and refugees present important public health challenges. Social and structural determinants affect both the general health and SRHR of migrants, but the drivers of SRHR among migrant and refugee populations remain understudied.
\end{abstract}

Aims: To identify upstream social and structural determinants of SRHR health of migrants and refugees reported in systematic reviews.

Methods: We conducted a systematic review of reviews. We studied 3 aspects of SRHR: sexually transmitted infections, sexual violence and unintended pregnancy in migrants and refugees. We used an inductive approach to synthesize emerging themes, summarized them in a narrative format and made an adapted version of Dahlgren and Whitehead's social determinants of health (SDH) model.

Results: We included 12 systematic reviews, of which 10 were related to sexually transmitted infections, 4 to sexual violence and 2 to unintended pregnancy. We identified 6 themes that operate at 4 different levels in an adapted version of the Dahlgren and Whitehead SDH model: economic crisis and hostile discourse on migration; limited legal entitlements, rights and administrative barriers; inadequate resources and financial constraints; poor living and working conditions; cultural and linguistic barriers; and stigma and discrimination based on migration status, gender, sex and ethnicity.

Conclusion: This review provides evidence of how upstream social and structural determinants undermine the SRHR of refugees and migrants. Unless these are addressed in policy-making and planning, the health of migrants and refugees is at risk.

Keywords: migrants, refugees, sexual and reproductive health, social and structural determinants of health

Citation: Egli-Gany D; Aftab W; Hawkes S; Abu-Raddad L; Buse K; Rabbani F; et al. The social and structural determinants of sexual and reproductive health and rights in migrants and refugees: a systematic review of reviews. East Mediterr Health J. 2021;27(12):1203-1213. https://doi.org/10.26719/ emhj.20.101

Received: 06/10/19; accepted: 19/05/20

Copyright (C) World Health Organization (WHO) 2021. Open Access. Some rights reserved. This work is available under the CC BY-NC-SA 3.0 IGO license (https://creativecommons.org/licenses/by-nc-sa/3.o/igo).

\section{Introduction}

The sexual and reproductive health and rights (SRHR) of migrants and refugees are important public health issues $(1,2)$. While migration brings opportunities for better lives and prosperity, it also increases risks to health for diverse and heterogeneous groups of people (1). Most migrants are of working age (3), including the peak age groups for sexual activity and have a range of related health problems (4). Today, most of the world's 258 million international migrants live in low- and middle-income countries (LMICs) $(1,3)$, which also experience a high burden of poor SRHR outcomes (5). Due to political upheaval and conflict, the Eastern Mediterranean Region hosts 66\% of the world's refugees and $33 \%$ of asylum seekers (6). In 2018, a large proportion of asylum seekers arriving in European Union (EU) Member States originated from the Eastern Mediterranean Region (7).
The SRHR of migrants is closely linked to political, environmental and cultural conditions. Migration is recognized as a social determinant of health (SDH) (9) by the International Organization for Migration (IOM) $(8,10)$ and the World Health Organization (11) because the conditions surrounding migration lead to health inequalities, increased health risks and negative health outcomes (8). The SDH provide a model for understanding the social and structural factors that influence health at different levels according to their causal proximity to a health problem; upstream and distal (such as general socioeconomic and environmental conditions) or downstream and proximal (individual factors) (Figure 1) (12,13). Understanding the underlying causes of poor health is crucial as they are likely to have greater impact on population health than individually targeted approaches $(14,15)$. Population level health can be improved through shifts in public policies and targeting upstream determinants of population health (14). 
Figure 1 The social and structural determinants of health [source: Dahlgren \& Whitehead (12)]

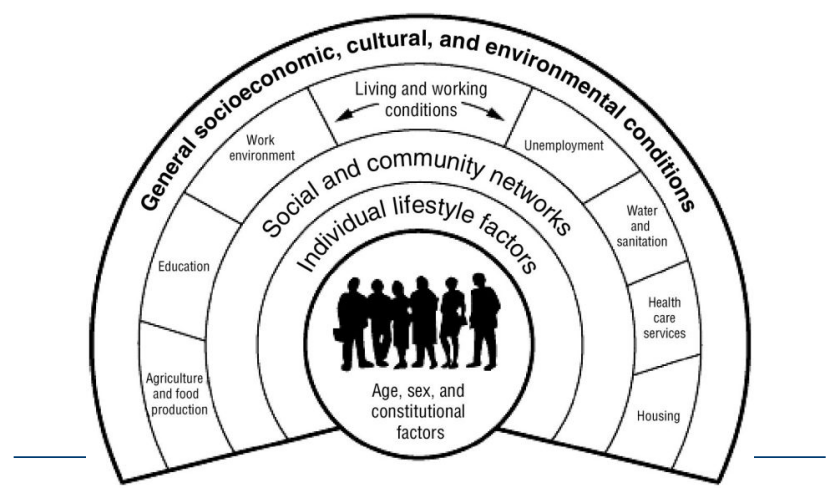

Structural and social factors are responsible for a major proportion of health inequalities (16). For disadvantaged populations, these factors relate to higher risks, reduced access to services leading to poorer disease outcomes, and worse economic and social outcomes related to poor health and the costs of treatment (17). In addition, global aspirations for the health-related targets of the Sustainable Development Goals, including universal health coverage, cannot be fulfilled without ensuring that all migrants are able to realize their rights, including in relation to sexual and reproductive health and rights (18). We conducted a systematic review to identify the structural and social determinants which put migrants and refugees at risk of poor SRHR outcomes, and to locate key policy areas where action can address inequalities in health.

The aim of this review was to identify upstream social and structural determinants of SRHR of migrants and refugees reported in systematic reviews. We addressed 3 aspects of SRHR outcomes: sexually transmitted infections (STIs), including hepatitis B and C and HIV/ AIDS; sexual violence; and unintended pregnancies, along with access to health care for the prevention and treatment of these outcomes. Results related to health in general were included where they also applied to SRHR.

\section{Methods}

\section{Design}

We conducted a review of systematic reviews following guidance from the Joanna Briggs Institute methodology group (19). We included systematic reviews which provided methods sufficiently detailed to be reproduced by another researcher. The protocol is registered on the electronic PROSPERO (international prospective register of systematic reviews) database (20) (PROSPERO CRD42018086039).

\section{Search strategy}

We searched the PubMed/MEDLINE and Web of Science (Science and Social Science Citation Index) electronic databases from 1 January 1980 to 9 February 2018. The search strategy included terms for the SHRH outcomes and populations of interest. For PubMed/MEDLINE, the terms were combined with a filter for reviews (21); this search strategy is published (20). We restricted our search to reviews published in English or German.

\section{Population of interest}

Our population of interest was international migrants, refugees and/or asylum seekers. We included systematic reviews that reported results for the population of interest separately. We excluded articles that did not give a definition for the target population that coincided with a definition from the IOM (22) or the United Nations High Commissioner for Refugees (UNHCR) (23). In brief, migrants include "all cases where the decision to migrate was taken freely by the individual concerned for reasons of "personal convenience"' (22); refugees include any "person who meets the eligibility criteria under the applicable refugee definition" (23) and asylum seekers include any "individual who is seeking international protection ... whose claim has not yet been finally decided on" (22). We included systematic reviews that reported findings for any of these defined populations. We excluded articles that did not give clear definitions of the study populations. We also excluded articles that only included data for (internal) domestic migrants, rural-to-urban migrants and internally displaced individuals.

\section{Social and structural determinants of interest}

Our review focussed on the upstream social and structural determinants of health from Dahlgren and Whitehead's SDH model and did not examine individual-level factors (Figure 1) (12).

\section{Review screening, selection, analysis and synthesis}

One researcher screened the titles and/or abstracts of retrieved articles, assessed the full text of potentially eligible articles and extracted data about review characteristics and determinants of the SRHR outcomes. A second reviewer checked all full-text inclusion and exclusion decisions and the extracted data. Discrepancies were resolved through discussion. Following an inductive approach, all authors discussed the included reviews and agreed upon emerging themes. We synthesized emerging themes and displayed them in an adapted version of Dahlgren and Whitehead's SDH model. We reported the findings narratively, using terms for SRHR outcomes that the authors of the included systematic reviews used.

\section{Results}

\section{Selection}

We screened 440 articles and included 11 systematic reviews that fulfilled our selection criteria (24-34) (Figure 2). Twenty-eight articles were excluded because there was no IOM or UNHCR population definition. On re-examination, we included one of these 28 reviews because it identified a new theme (economic crisis) (35). The 12 


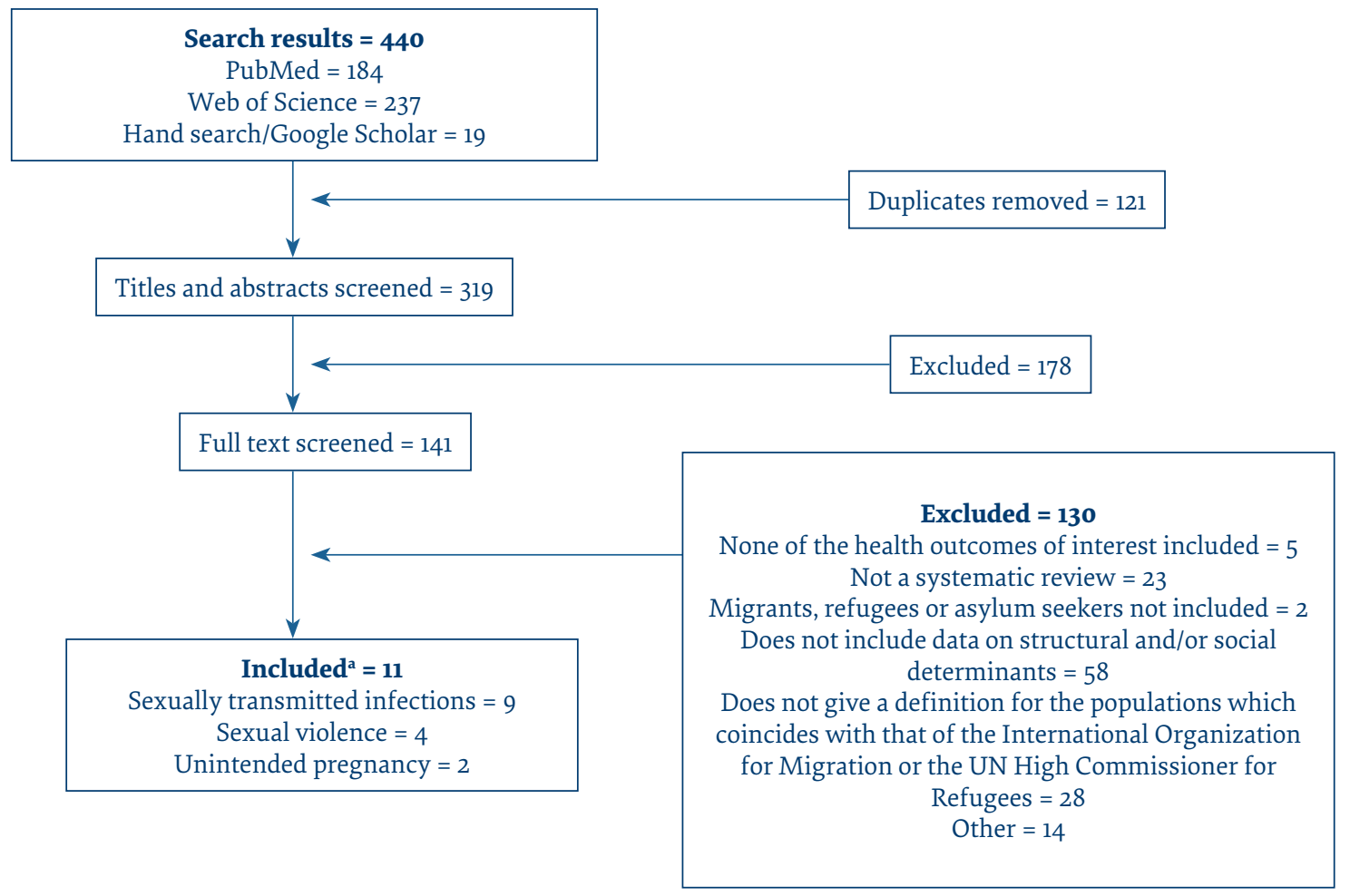

reviews included a median of 38 articles (interquartile range 29-45). Table 1 reports the characteristics of the included reviews. Ten of the 12 reviews examined health outcomes related to STIs $(24-29,31,33-35), 4$ to sexual violence (29-32) and 2 to unintended pregnancies $(25,27)$. Most reviews included studies with both qualitative (10/12) and quantitative (9/12) data. The reviews included migrants and/or refugees originating from sub-Saharan Africa (8/12), Asia (7/12), Latin America (7/12), the Middle East and North Africa (MENA) (6/12), Europe (6/12), Oceania (2/12) and North America (1/12). All reviews included Europe as a receiving region, whereas Asia, Latin America, MENA, and sub-Saharan Africa were receiving regions in less than half of the included reviews.

\section{Data synthesis}

We identified 6 themes (Table 2 ) that operate at 4 different levels in our adaptation of the Dahlgren and Whitehead SDH model (Figure 3): prevailing norms and narratives, structural determinants, living and working conditions and social and community factors. The themes are:

- Economic crises and hostile discourse on migration Our findings show that the general tenor of societal discourse on migration and migrants influences the perceptions of host communities and migrants themselves about the acceptability of using resources for SRHR needs of migrants (27,34). Anti-immigrant rhetoric, especially against undocumented migrants, draws attention to economic crises (34); when migration is framed as a threat to the economy and a burden on health systems, it negatively influences public opinion and constrains migrants' SRHR choices as they fear being perceived as "using too many resources" (27). Influenced by anti-immigrant rhetoric and policies, providers may deny needed SRHR services to undocumented migrants, who may feel too threatened to seek care (34). During economic crises in Europe, there is evidence of a disproportionately higher risk of STIs among migrants related to unemployment and poverty, which directly create the conditions for STI transmission and austerity measures and cuts to prevention and treatment programmes (35).

- Limited legal entitlements, rights and administrative barriers. A comprehensive literature review from the EU found that the right to health, including access to health care, for migrants is influenced by competing policy narratives and frameworks, e.g. rights versus immigration; the latter mostly emphasizing immigration control. In practice, this contradiction can deter migrants from seeking care, especially undocumented ones (27). The review found a general lack of policies, regulations and guidelines on migrant SRHR (27). In the $\mathrm{EU}$, legal entitlements to care varies with the type of migrant and is particularly restrictive for undocumented migrants (27). Most recent policies in the EU focus only on asylum seekers and refugees. In many EU countries, undocumented migrants only have access to emergency services. The definition of "emergency services" varies across countries and is 


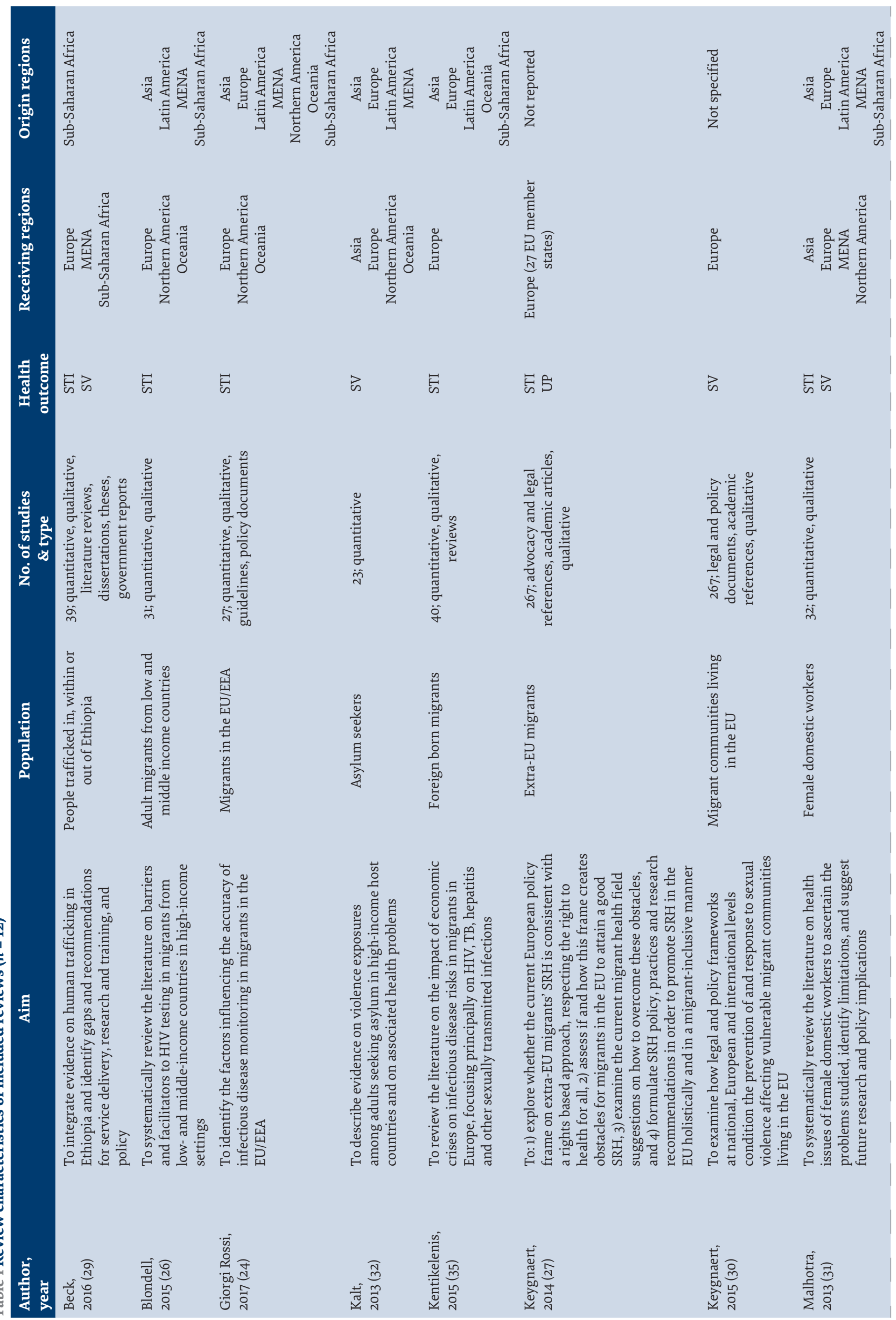




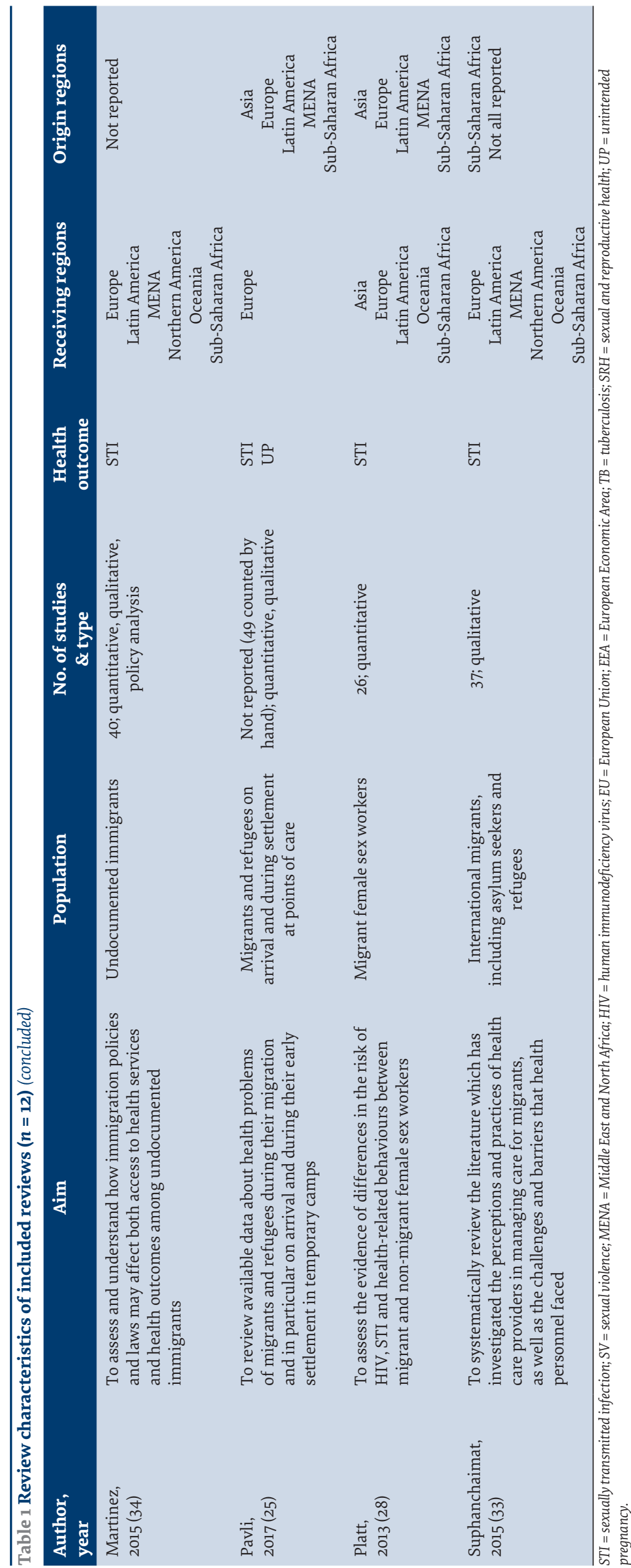

subject to change, creating uncertainty about entitlement to sexual and reproductive health (SRH) care. In the United Kingdom, HIV treatment used to be an emergency service but this was rescinded in 2009, thus ending free HIV treatment for all (27). Many European countries restrict undocumented migrants from accessing treatment for hepatitis $\mathrm{C}$ and HIV infections (25). As a result, documented migrants from LMICs in high-income countries (HICs) have comparatively better access to HIV testing than undocumented migrants, whose legal status and fear of deportation act as deterrents to HIV testing (26). The absence of regional guidelines on HIV testing among migrants also poses a barrier to HIV testing in HICs (26). In the EU, few policy documents address both SRHR and migrants (27). The legal provisions on migrant SRHR focus on a narrow understanding of reproductive health, concentrating mainly on pregnant women and neglecting important dimensions (27), e.g. sexual violence in highly vulnerable migrant sub-groups (30). Most policy documents dealing with sexual violence do not consider sexual violence against men, undocumented migrants and sex workers. The effect of structural factors, such as legal status and living conditions, on predilection to sexual violence is also ignored. While sexual violence in the countries of origin (e.g. in war, during trafficking or female genital mutilation) is considered, the potential for sexual violence against vulnerable migrants after arriving in the EU is ignored; the exception is sexual violence in migrant accommodation centres (30). As a result, migrants vulnerable to sexual violence face significant legal obstacles in realizing their rights to SRH services in the $\mathrm{EU}(30)$. Fulfilling the administrative requirements needed to access care can be prohibitive for migrants as well as providers. For instance, when requirements such as proof of residence (27), insurance $(24,27)$ or resources $(27)$ are unclear, they create uncertainty about entitlement for both migrants and providers (27). Moreover, differing entitlements for various groups of migrants make it difficult for medical and administrative staff to determine which services can be offered (27). The situation is more complicated for undocumented migrants. Even when legally entitled, de facto access to care can be limited by administrative and financial burdens (33).

- Inadequate resources and financial constraints. The limited finances and resources available for the SRHR of migrants and refugees delay needed diagnosis and treatment. Lack of financial allocation for migrant health, including preventive services, results in subop- 
Table 2 Summary of the upstream social and structural determinants of sexual and reproductive health and rights of migrants and refugees

\begin{tabular}{|c|c|c|}
\hline Determinant theme & Reference Nos. & Summary \\
\hline $\begin{array}{l}\text { 1. Economic crises and hostile discourse } \\
\text { on migration }\end{array}$ & $27,34,35$ & $\begin{array}{l}\text { Economic crises, impoverishment, austerity measures, anti-immigrant rhetoric, } \\
\text { public opinion and policies puts migrants at risk of sexual ill health and limits } \\
\text { access to care }\end{array}$ \\
\hline $\begin{array}{l}\text { 2. Limited legal entitlements, rights and } \\
\text { administrative barriers }\end{array}$ & $24,25,26,27,30,33$ & $\begin{array}{l}\text { Lack of policies on migrant SRHR, restricted entitlements to SRH services, } \\
\text { exclusion of undocumented migrants, narrow policy focus on reproductive health } \\
\text { and specific populations, lack of policy focus on migrant populations vulnerable to } \\
\text { sexual violence as well as burdensome administrative requirements are barriers to } \\
\text { good SRHR }\end{array}$ \\
\hline $\begin{array}{l}\text { 3. Inadequate resources and financial } \\
\text { barriers }\end{array}$ & $26,27,30,33,34$ & $\begin{array}{l}\text { Limited financial and human resources in the health care sector, out-of-pocket } \\
\text { expenses and transport and housing costs undermine the SRHR of migrants }\end{array}$ \\
\hline 4. Poor living and working conditions & $26,27,28,29,31,32$ & $\begin{array}{l}\text { Frequent relocation, living in underserved areas, inaccessible location of health } \\
\text { services, legal status of occupations, living in detention/reception centres, poor } \\
\text { working conditions and poverty are associated with poor SRH in migrants }\end{array}$ \\
\hline 5. Cultural and linguistic barriers & $\begin{array}{l}24,25,26,27,29 \\
31,33\end{array}$ & $\begin{array}{l}\text { Different languages, communication and cultural norms between health care } \\
\text { providers, migrants and the community are barriers to adequate SRH diagnosis } \\
\text { and treatment }\end{array}$ \\
\hline 6. Stigma and discrimination & $26,27,29,30,32$ & $\begin{array}{l}\text { Stigma and discrimination related to migration status, sex, gender, sexual } \\
\text { orientation and pregnancy outside marriage negatively impact the SRHR of } \\
\text { migrants }\end{array}$ \\
\hline
\end{tabular}

SRH = sexual and reproductive health; SRHR = sexual and reproductive health and rights.

timal levels of HIV testing of migrants from LMICs (26). While accessing care after an AIDS diagnosis, Latino migrants in United States were prevented from accessing care because of bureaucratic requirements and generally poor access to health care (34). Requirements for out-of-pocket payments create direct financial barriers, especially for undocumented migrants, while housing and transport costs are indirect financial constraints (27). Inadequate financial and human resources (e.g. health providers, interpreters) have been identified as barriers to adequate migrant health care by health providers (33), while nongovernmental agencies have raised concerns about limited funding, which negatively affects care for migrants affected by sexual violence (30).

- Poor living and working conditions. Migrants move regularly and live in underserved areas, creating barriers to health care access and contributing to poor SRHR (27). Alternatively, offering services in easily accessible places facilitates HIV testing in HICs (26). Legal stipulations about sex work and their own legal status may deter migrant sex workers from seeking care (27). Adverse working conditions, such as confiscation of passports and withholding of food, are associated with abuse at the workplace among female domestic workers (31), which may lead to sexual violence. Living in detention and reception centres is associated with being subjected to violence. In one systematic review, the prevalence of sexual violence in these centres in HICs ranged from $13.6 \%$ to $77.8 \%$ (32). Poverty has also been associated with human trafficking and subsequent sexual violence (29). Evidence about migrant SRHR in LMICs is more limited. One review found that migrant female sex workers in lower income countries were at higher risk of HIV than non-migrant sex workers (28).

- Cultural and linguistic barriers. Communication, language and cultural problems related to the migration process influence access to health services across the EU for arriving migrants and refugees (25). Communication and language problems limit the effectiveness of health promotion activities targeted at migrants (26), make it difficult for migrants to navigate health systems (27), and prevent health workers from providing adequate services to $\mathrm{mi}$ grants (33). For instance, the inability of migrants to effectively communicate signs and symptoms of illness could decrease the probability of syndromic diagnosis of infections (24), potentially leading to inadequate management of HIV and STIs. Cultural attitudes and beliefs among both migrants and providers can act as barriers to adequate SRH of migrants. For example, suboptimal knowledge, attitudes and practices about SRH puts female domestic workers at higher risk of STIs (31). Health providers consider cultural differences between health providers and migrant patients, professional norms, and poor cultural fit of service provision guidelines as barriers to delivery of quality care (33). The lack of cultural sensitivity of health care providers limits uptake of HIV testing among migrants (26). Sociocultural factors (e.g. early child marriage, lack of access to social services, etc.) leave women and children vulnerable to human trafficking and subsequent sexual violence (29).

- Stigma and discrimination. Discrimination based on migration status, gender, sex and ethnicity impact migrant SRH. Migration status intersects with other factors such as race, ethnicity and gender to exclude 
Figure 3 The social and structural determinants of sexual and reproductive health and rights in migrants and refugees (The box lists the six social and structural determinant themes identified in this review. The four levels of the rainbow (social and community; living and working conditions; structural determinants; prevailing norms and narratives) represent the different levels at which these determinants operate. The layers of the rainbow are populated with the main results of this review. The roman numerals indicate the related determinant theme)

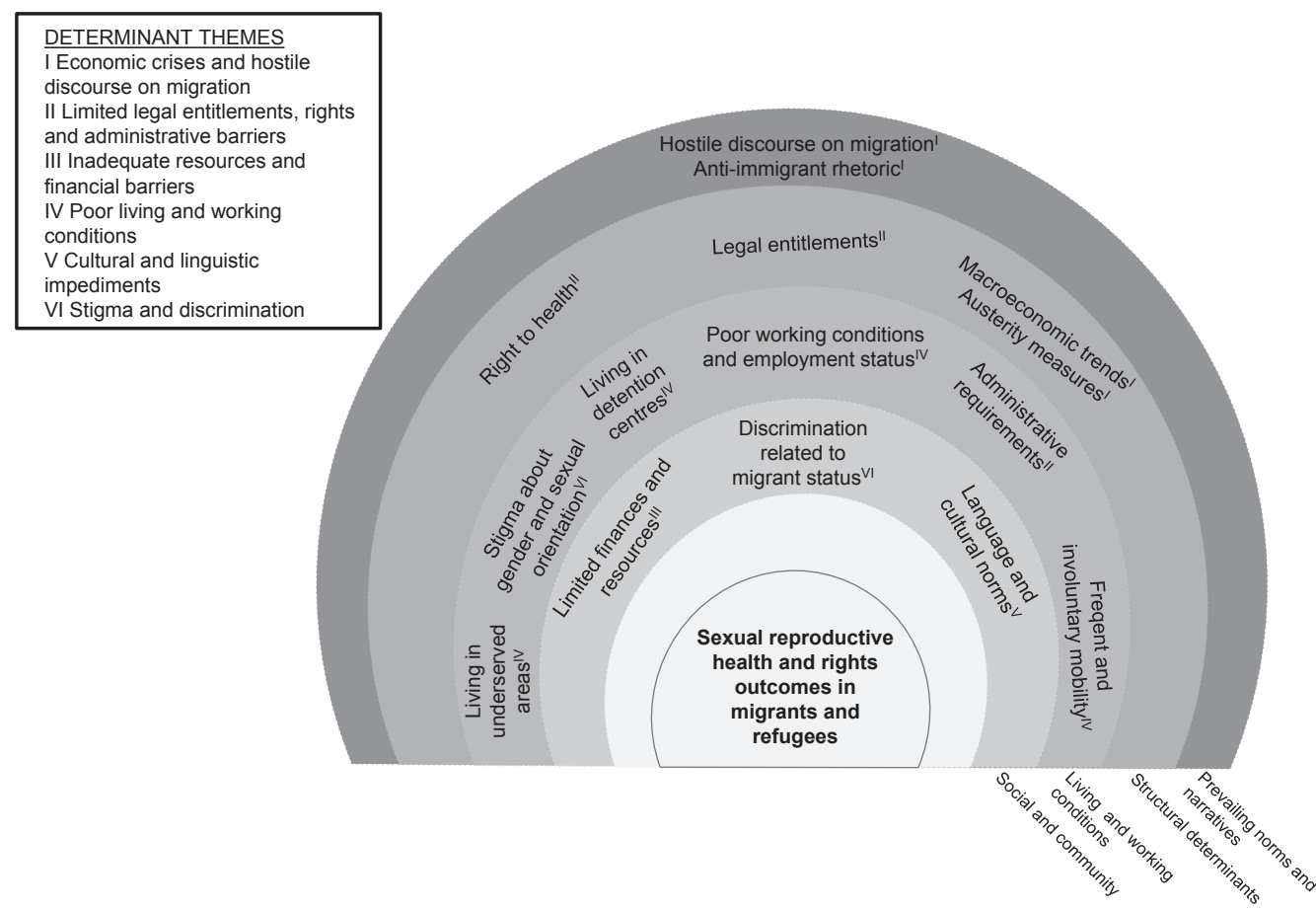

migrants, particularly women, from accessing care (27). Gender discriminatory practices were found to be a risk factor for human trafficking in, within and outside of Ethiopia, which results in migrants experiencing poor health outcomes and sexual violence (29). Female asylum seekers have a higher risk of sexual torture compared with males (32). Stigma was reported as a barrier to accessing health care $(26,27,29)$. Perceived and experienced stigma have been reported as significant barriers to HIV testing across migrant groups in HICs (26). Pregnancy outside marriage and the associated stigma were also identified as a factor leaving women vulnerable to trafficking and subsequently poor SRHR outcomes (29). Migrant male sex workers are particularly vulnerable to sexual violence due to stigma associated with migrant status, sex work and homosexuality, yet this vulnerability is not acknowledged in sexual violence policies in Europe (30).

\section{Discussion}

\section{Summary of main findings}

This review provides evidence about social and structural determinants that preclude migrants and refugees from maintaining good SRH and realizing their right to enjoyment of the highest attainable standard of health (36). We identified 6 determinants (Table 2), operating at 4 levels (Figure 3). Our findings align with research on underlying causes of poor migrant health $(1,9,10,37)$. Our review adds new knowledge about how multiple determinants are harmful to SRHR. Economic crises; hostile environments; and limited legal entitlements, rights and policies exclude migrants from realizing their right to health and health care. Inadequate financial and human resources limit the health care services offered and care-seeking. Poor living and working conditions are associated with poor SRHR. Different languages and cultural norms between health care providers, migrants and the community are barriers to adequate diagnosis and treatment. Stigma and discrimination related to migration status, sex, gender and sexual orientation negatively impact the SRHR of migrants. Furthermore, our adapted model of determinants is relevant beyond the specific findings of this review and links upstream determinants (narratives and values) to health inequalities (Figure 3).

\section{Strengths and limitations}

The strengths of this review include the systematic search, the identification of the most consistent upstream determinants of migrant and refugee SRHR, and our adaptation of a widely used SDH framework (12). Our focus on STIs, sexual violence and unintended pregnancies is likely to have narrowed the number of identified determinants. The review of systematic reviews, rather than primary studies, might be seen as a limitation. In a research field as broad as the health of diverse groups of migrants and refugees, however, we were able to take advantage of existing systematic searches to compile 
the most relevant literature pertinent to various migrant sub-populations.

\section{Implications for research and policy}

Our review identified upstream social and structural determinants that impact migrants' SRHR, but many reviews focused on downstream determinants. Given the politicized debates and growing xenophobic rhetoric and actions targeting migration (38), research about upstream determinants is an important priority. Our review identified findings mainly coming from HICs; research is lacking from the Eastern Mediterranean Region and other regions with larger fluxes of migrants and refugees (39) as are studies on unintended pregnancies and sexual violence in these populations. Research is also needed to connect knowledge of identified determinants and effective policies to mitigate the effect of these structural inequities, including rights-based approaches to improve the SRHR of migrants. Moreover, research into differing norms, power and political prioritization is needed to understand why SRHR among migrants remains a de-prioritized area.

Our review examined determinants of 3 selected SRHR outcomes. The nature of these determinants depends on context and relates to different populations of migrants and refugees - leading to caution in overt generalizations. Nevertheless, some potential policy implications arising from our review should be highlighted. First, to address key structural barriers to SRHR, sectors beyond health must be engaged. Second, the scope of migrant SRHR policies should be expanded to include areas such as sexual violence. Responses to sexual violence in host countries should be based on the consideration that migrants and refugees are at risk of sexual violence in countries of origin, in transit and in destination countries and need appropriate legal and health system protections. Third, in an era of austerity, preventive and curative SRH services for migrants, including undocumented migrants, and refugees must be adequately resourced in order to respect, protect and fulfil the right to health. Finally, evidence-informed SRHR services should be delivered in culturally sensitive ways to ensure uptake, provide appropriate linguistic support and assure privacy, confidentiality and dignity.

\section{Conclusion}

This review provides evidence for how upstream social and structural determinants undermine the SRHR of refugees and migrants. Unless these are addressed in policy-making and planning, the health and rights of migrants and refugees is at risk.

\section{Acknowledgement}

We thank Beatrice Minder for her assistance with developing the search strategy for this review, Carole Frenzer for her assistance with data verification and Anna Purdie for her input in conceptualizing the study. Dianne Egli-Gany and Wafa Aftab are joint authors and have contributed equally to this work.

Funding: This work was conducted as part of the SELMA project (Sexual Health Policy for Migrants) funded by the Volkswagen Stiftung, Riksbankens Jubileumsfond and the Wellcome Trust (208712/Z/17/Z).

Competing interests: None declared.

\section{Déterminants sociaux et structurels de la santé sexuelle et reproductive et droits associés chez les migrants et les réfugiés : examen systématique d'analyses}

\section{Résumé}

Contexte : La santé sexuelle et reproductive et les droits associés des migrants et des réfugiés présentent d'importants défis en matière de santé publique. Les déterminants sociaux et structurels ont une incidence à la fois sur la santé générale et sur la santé sexuelle et reproductive et les droits associés des populations de migrants et de réfugiés, mais les facteurs qui influencent ces derniers demeurent sous-étudiés.

Objectifs : Identifier les déterminants sociaux et structurels intervenant en amont de la santé sexuelle et reproductive et des droits associés des migrants et des réfugiés, tels que décrits dans les examens systématiques.

Méthodes : Nous avons procédé à un examen systématique d'analyses. Nous avons étudié trois aspects de la santé sexuelle et reproductive et des droits associés : les infections sexuellement transmissibles, les violences sexuelles et les grossesses non désirées chez les migrants et les réfugiés. Nous avons utilisé une approche inductive pour synthétiser les thèmes émergents, puis les avons résumés dans un format narratif et avons réalisé une version adaptée du modèle de Dahlgren et Whitehead sur les déterminants sociaux de la santé.

Résultats : Nous avons inclus 12 examens systématiques, dont 10 étaient liés aux infections sexuellement transmissibles, quatre aux violences sexuelles et deux aux grossesses non désirées. Nous avons identifié six thèmes qui interviennent à quatre niveaux différents dans une version adaptée du modèle sur les déterminants sociaux de la santé de Dahlgren et Whitehead : la crise économique et les discours hostiles à la migration ; les droits légaux limités, les obstacles juridiques et administratifs ; les ressources insuffisantes et les contraintes financières ; les mauvaises 
conditions de vie et de travail ; les barrières culturelles et linguistiques ; et la stigmatisation et la discrimination basées sur le statut migratoire, le genre, le sexe et l'ethnicité.

Conclusion : La présente analyse montre comment les déterminants sociaux et structurels intervenant en amont nuisent à la santé sexuelle et reproductive et aux droits associés des réfugiés et des migrants. Tant que ces éléments ne sont pas pris en compte dans l'élaboration des politiques et la planification, la santé des migrants et des réfugiés est en danger.

$$
\begin{aligned}
& \text { المحددات الاجتماعية والهيكلية للصحة الجنسية والإنجابية للمهاجرين واللاجئين والحقوق المتعلقة بها: استعر اض } \\
& \text { منهجي للاستعر اضات الاجتية } \\
& \text { ديان إيجلي-جيني، وفاء أفتاب، سارة هوكس، ليث أبو رداد، كينت بوس، فوزيه رباني، نيكولا لا لو، كريستين أونارهايم }
\end{aligned}
$$

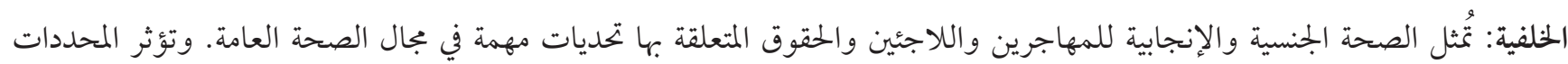

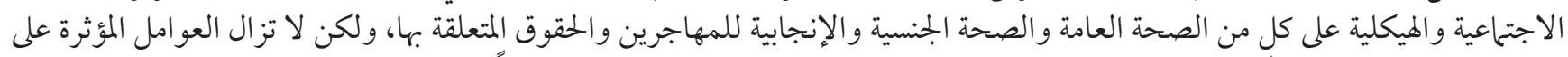

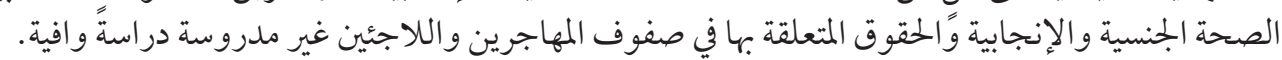

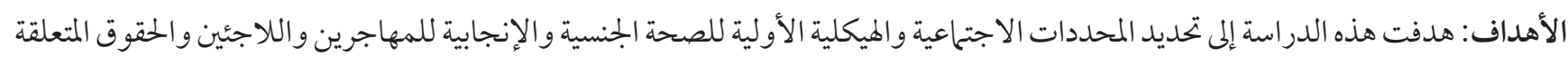

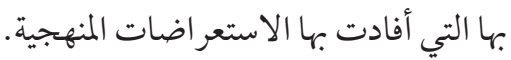

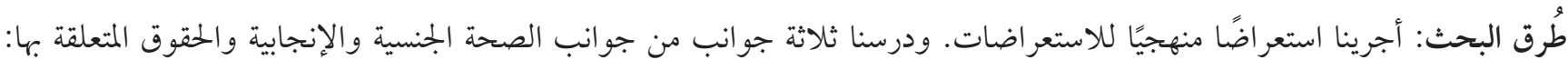

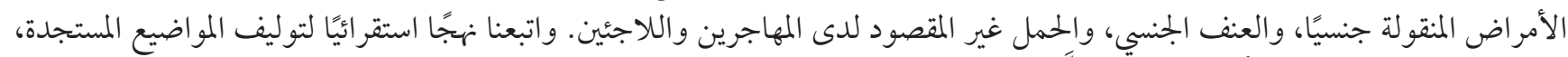

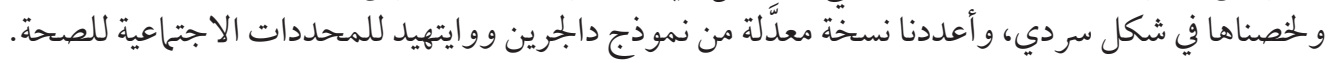

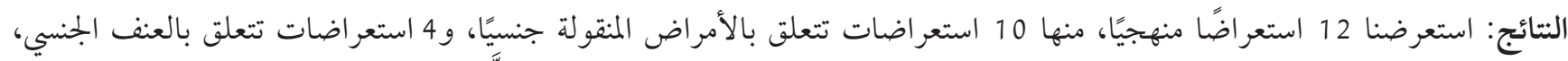

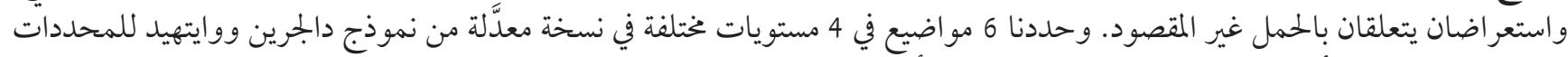

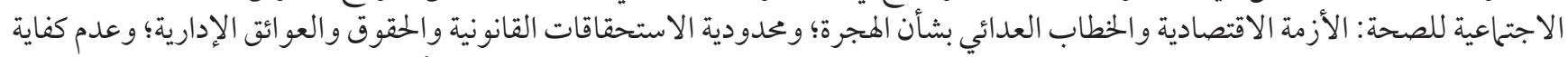

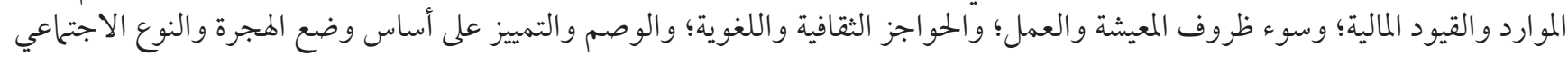

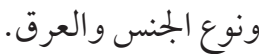

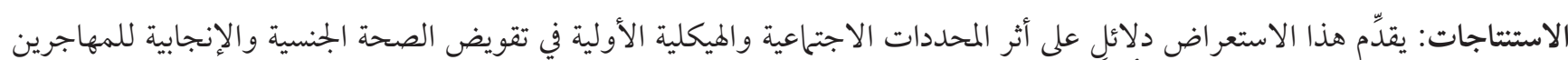

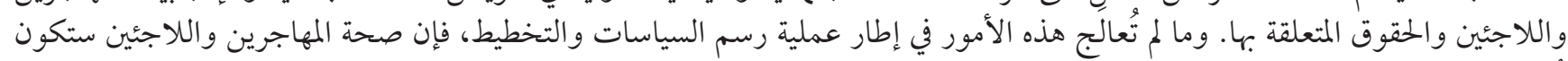
عُرضة للخطر.

\section{References}

1. Abubakar I, Aldridge RW, Devakumar D, Orcutt M, Burns R, Barreto ML, et al. The UCL-Lancet Commission on Migration and Health: the health of a world on the move. Lancet. 2018;392(10164):2606-54. doi:10.1016/So140-6736(18)32114-7

2. Starrs AM, Ezeh AC, Barker G, Basu A, Bertrand JT, Blum R, et al. Accelerate progress - sexual and reproductive health and rights for all: report of the Guttmacher-Lancet Commission. Lancet. 2018;391(10140):2642-92. doi:10.1016/So140-6736(18)30293-9

3. Global migration indicators 2018. Berlin: International Organization for Migration; 2018.

4. GBD results tool. Seattle: Institute for Health Metrics and Evaluation, Global Health Data Exchange; 2018 (http://ghdx.healthdata.org/gbd-results-tool, accessed 26 September 2019).

5. Rowley J, Vander Hoorn S, Korenromp E, Low N, Unemo M, Abu-Raddad LJ, et al. Chlamydia, gonorrhoea, trichomoniasis and syphilis: global prevalence and incidence estimates, 2016. Bull World Health Organ. 2019;97(8):548-62. doi:10.2471/BLT.18.22848

6. International health regulations (IHR). Geneva: World Health Organization; 2019 (http://www.emro.who.int/international-health-regulations/ihr-news/promoting-health-of-migrants-and-displaced-populations-in-the-eastern-mediterranean-region. html, accessed 22 August 2019).

7. Asylum statistics. Luxembourg: European Commission, Eurostat; 2019 (https://ec.europa.eu/eurostat/statistics-explained/index. php/Asylum_statistics\#Citizenship_of_first-time_applicants:_largest_shares_from_Syria.2C_Afghanistan_and_Iraq, accessed 05 September 2019).

8. Social determinants of migrant health. Geneva: International Organization for Migration; 2019 (https://www.iom.int/social-determinants-migrant-health, accessed 20 February 2020). 
9. Castañeda H, Holmes SM, Madrigal DS, Young M-ED, Beyeler N, Quesada J. Immigration as a social determinant of health. Annu Rev Public Health. 2015;36(1):375-92. doi: 10.1146/annurev-publhealth-032013-182419

10. Davies A, Basten A, Frattini C. Migration: a social determinant of the health of migrants. Geneva: International Organization for Migration; 2009 (https://ec.europa.eu/migrant-integration/index.cfm?action=media.download\&uuid=2AA986F7-DBA1-D96C9028652AF54FC2C1, accessed 24 June 2020).

11. Review of social determinants and the health divide in the WHO European Region: final report. World Health Organization Regional Office for Europe: Copenhagen; 2013.

12. Dahlgren G, Whitehead M. Policies and strategies to promote social equity in health. Stockholm: Institute of Future Studies; 1991.

13. Commission on Social Determinants of Health. Closing the gap in a generation: health equity through action on the social determinants of health. Geneva: World Health Organization; 2008.

14. Thornton RL, Glover CM, Cene CW, Glik DC, Henderson JA, Williams DR. Evaluating strategies for reducing health disparities by addressing the social determinants of health. Health Aff (Millwood). 2016;35(8):1416-23. doi:10.1377/hlthaff.2015.1357

15. Frieden TR. A framework for public health action: the health impact pyramid. Am J Public Health. 2010;100(4):590-5. doi:10.2105/ AJPH.2009.185652

16. Donkin A, Goldblatt P, Allen J, Nathanson V, Marmot M. Global action on the social determinants of health. BMJ Glob Health. 2018;3(Suppl. 1):e000603. doi:10.1136/bmjgh-2017-000603

17. Solar O, Irwin A. A conceptual framework for action on the social determinants of health. Social determinants of health discussion paper 2 (policy and practice). Geneva: World Health Organization; 2010 (https://www.who.int/sdhconference/resources/ ConceptualframeworkforactiononSDH_eng.pdf, accessed 24 June 2020).

18. Pant S, Eder B, Vracar A, Mosca D, Orcutt M. WHO's global action plan to promote the health of refugees and migrants. BMJ. 2019;366:14806. doi:10.1136/bmj.l4806

19. Aromataris E, Fernandez R, Godfrey CM, Holly C, Khalil H, Tungpunkom P. Summarizing systematic reviews: methodological development, conduct and reporting of an umbrella review approach. Int J Evid Based Healthc. 2015;13(3):132-40. doi:10.1097/ XEB.0000000000000055

20. Egli-Gany D, Low N, Hawkes S, Onarheim K, Aftab W. Social and structural determinants of sexual and reproductive health in migrant and refugee populations: a systematic review of reviews. 2018 (https://www.crd.york.ac.uk/prospero/display_record. php?RecordID=86039, accessed 25 June 2020).

21. Search strategy used to create the systematic subset on PubMed. Bethesda, Maryland: National Library of Medicine; 2017 (https://www.nlm.nih.gov/bsd/pubmed_subsets/sysreviews_strategy.html, accessed 25 June 2020).

22. Glossary on migration. Geneva: International Organization for Migration; 2011.

23. Master glossary of terms. Geneva: United Nations High Commissioner for Refugees; 2006 (https://www.refworld.org/pdfid/42ce7d444.pdf, accessed 24 June 2020).

24. Giorgi Rossi P, Riccardo F, Pezzarossi A, Ballotari P, Dente MG, Napoli C, et al. Factors influencing the accuracy of infectious disease reporting in migrants: a scoping review. Int J Environ Res Public Health. 2017;14(7):720). doi:10.3390/ijerph14070720

25. Pavli A, Maltezou H. Health problems of newly arrived migrants and refugees in Europe. J Travel Med. 2017;24(4):1-8. doi:10.1093/jtm/taxo16

26. Blondell SJ, Kitter B, Griffin MP, Durham J. Barriers and facilitators to HIV testing in migrants in high-income countries: a systematic review. AIDS Behav. doi:10.1007/s10461-015-1095-x 2015;19(11):2012-24.

27. Keygnaert I, Guieu A, Ooms G, Vettenburg N, Temmerman M, Roelens K. Sexual and reproductive health of migrants: does the EU care? Health Policy. 2014;114(2-3):215-25. doi:10.1016/j.healthpol.2013.10.007

28. Platt L, Grenfell P, Fletcher A, Sorhaindo A, Jolley E, Rhodes T, et al. Systematic review examining differences in HIV, sexually transmitted infections and health-related harms between migrant and non-migrant female sex workers. Sex Transm Infect. 2013;89(4):311-9. doi:10.1136/sextrans-2012-050491

29. Beck DC, Choi KR, Munro-Kramer ML, Lori JR. Human trafficking in Ethiopia: a scoping review to identify gaps in service delivery, research, and policy. Trauma Violence Abuse. 2017;18(5):532-43. doi:10.1177/1524838016641670

30. Keygnaert I, Guieu A. What the eye does not see: a critical interpretive synthesis of European Union policies addressing sexual violence in vulnerable migrants. Reprod Health Matters. 2015;23(46):45-55. doi:10.1016/j.rhm.2015.11.002

31. Malhotra R, Arambepola C, Tarun S, de Silva V, Kishore J, Ostbye T. Health issues of female foreign domestic workers: a systematic review of the scientific and gray literature. Int J Occup Environ Health. 2013;19(4):261-77. doi:10.1179/204939671 3Y.0000000041

32. Kalt A, Hossain M, Kiss L, Zimmerman C. Asylum seekers, violence and health: a systematic review of research in high-income host countries. Am J Public Health. 2013;103(3):e30-42. doi:10.2105/AJPH.2012.301136

33. Suphanchaimat R, Kantamaturapoj K, Putthasri W, Prakongsai P. Challenges in the provision of healthcare services for migrants: a systematic review through providers' lens. BMC Health Serv Res. 2015;15:390-404. doi:10.1186/s12913-015-1065-Z 
34. Martinez O, Wu E, Sandfort T, Dodge B, Carballo-Dieguez A, Pinto R, et al. Evaluating the impact of immigration policies on health status among undocumented immigrants: a systematic review. J Immigr Minor Health. 2015;17(3):947-70. doi:10.1007/ s10903-013-9968-4

35. Kentikelenis A, Karanikolos M, Williams G, Mladovsky P, King L, Pharris A, et al. How do economic crises affect migrants' risk of infectious disease? A systematic-narrative review. Eur J Public Health. 2015;25(6):937-44. doi:10.1093/eurpub/ckv151

36. CESCR General Comment No. 14. The right to the highest attainable standard of health (Art. 12). Geneva: Office of the High Commissioner for Human Rights; 2000 (https://www.refworld.org/pdfid/4538838do.pdf, accessed 24 June 2020).

37. Shannon K, Goldenberg SM, Deering KN, Strathdee SA. HIV infection among female sex workers in concentrated and high prevalence epidemics: why a structural determinants framework is needed. Curr Opin HIV AIDS. 2014;9(2):174-82. doi:10.1097/ COH.0000000000000042

38. Miller SD. Xenophobia toward refugees and other forced migrants. Waterloo, Canada: World Refugee Council; 2018:WRC Research Paper No. 5.

39. Sweileh WM, Wickramage K, Pottie K, Hui C, Roberts B, Sawalha AF, et al. Bibliometric analysis of global migration health research in peer-reviewed literature (2000-2016). BMC Public Health. 2018;18(1):777-95. doi:10.1186/s12889-018-5689-X 